\title{
Tolerance and Effect of a Probiotic Supplement Delivered in Capsule Form
}

\author{
Gina Labellarte, Margaret Maher \\ Biology Department, University of Wisconsin, La Crosse, USA \\ Email: mmaher@uwlax.edu
}

How to cite this paper: Labellarte, G. and Maher, M. (2019) Tolerance and Effect of a Probiotic Supplement Delivered in Capsule Form. Food and Nutrition Sciences, 10, 626-634.

https://doi.org/10.4236/fns.2019.106046

Received: May 10, 2019

Accepted: June 21, 2019

Published: June 24, 2019

Copyright $\odot 2019$ by author(s) and Scientific Research Publishing Inc. This work is licensed under the Creative Commons Attribution International License (CC BY 4.0).

http://creativecommons.org/licenses/by/4.0/

\begin{abstract}
Probiotic supplements have shown benefits in increasing frequency and efficiency of bowel movements and some strains have shown to reduce serum glucose levels. Bacillus subtilis is used in the fermentation of some foods for probiotic effects and may be useful in concentrated supplement form. The first objective of this clinical study was to determine if daily consumption of Bacillus subtilis strain DE111 at a dose of $5 \times 10^{9} \mathrm{CFU}$ is safe for human consumption. The second objective was to determine the effectiveness at increasing frequency of normal bowel movements and improving consistency of bowel type, by increasing beneficial gut microbes and reducing pathogenic ones. The tolerance and efficacy of encapsulated Bacillus subtilis DE111 was assessed in an average 20-day double-blind, randomized, and placebo-controlled human study. Most blood parameters remained within normal ranges throughout; however, fasted serum glucose levels in the probiotic group ( $91.0 \pm 1.0$ to $85.9 \pm 1.4 \mathrm{mg} / \mathrm{dl}, \alpha \leq 0.05 ; \mathrm{P}=0.012$ ) were significantly reduced. Although there was a significant increase in the average number of bowel movements per day within the placebo group $(\alpha \leq 0.05 ; \mathrm{P}=0.015)$, there was no significant change in the type. Triglyceride levels were maintained within the probiotic group, while the control group displayed a significant increase from pre to post by paired T-test $(\alpha \leq 0.05 ; \mathrm{P} \leq 0.042)$ (Figure 2). Additionally, significant differences in microbe colonization were present for Bacillus subtilis and Bifidobacterium in the fecal colony counts. Daily consumption of Bacillus subtilis can be recognized as safe, and has potential to be effective as a supplement to improve glucose tolerance.
\end{abstract}

\section{Keywords}

Bacillus subtilis, DE111, Digestive Health, Gastrointestinal Tract Microflora, Probiotic 


\section{Introduction}

The large intestines are colonized with 500 different species of bacteria [1] [2] with $10^{11} \mathrm{CFU} / \mathrm{g}$ colon tissue. Gut commensals, described as probiotics, exhibit various beneficial effects for the host [3]. Probiotics are live microorganisms passing through, or residing in, the human gut with little or no pathogenicity and exhibit beneficial effects for the host [1] [3] [4] [5]. Probiotic supplementation has shown positive results for the relief of various ailments, such as antibiotic-associated diarrhea, constipation, allergies, and diabetes [3] [5] [6] [7] [8] [9]. Probiotics have also exhibited protective properties by producing inhibitory substances, competitive inhibition of pathogenic bacteria, degrading toxin receptors, and stimulating the immune system [3] [4] [7] [10].

Common probiotics are lactic acid producers such as Lactobacillus, Bifidobacterium, and Streptococcus due to their resistance to gastric acids, bile salts, and pancreatic enzymes [3] [11]. Studies have shown that lactic acid bacteria are effective inhibitors of pathogenic, gram-negative, bacterial colonization (e.g. $S$. typhimurium, C. difficile, and E. coli) in vitro [1] [3].

B. subtilis are gram-positive, spore-forming, rod-shaped bacteria, which have been used as probiotics, competitive exclusion agents, and prophylactics for human and animal consumption [10]. The purpose of this study is to determine the tolerance and efficacy of daily ingestion of one capsule containing approximately $5 \times 10^{9}$ colony forming units (CFU)/capsule of B. subtilis. Tolerance was assessed through analysis of blood biomarkers within comprehensive clinical metabolic and liver panels, and immune-reactive C-reactive protein (CRP), a substance that reflects acute stress [12]. Tolerance was also assessed through a pre- and post-capsule consumption gastrointestinal symptom questionnaire. Efficacy was determined through blood biomarkers within comprehensive metabolic and lipid panels, bowel movement records, and pre- and post-capsule consumption fecal analyses.

\section{Methods}

Forty-one participants (19- 42 years of age) were recruited for participation in this study, as approved by the Institutional Review Board (IRB) for the Protection of Human Subjects at the University of Wisconsin-La Crosse, USA. The study was randomized and double-blinded with daily oral consumption of supplement (approximately $5 \times 10^{9} \mathrm{CFU} /$ capsule of B. subtilis, DE111) or placebo (maltodextrin) for an average of 20 days (range of 15 - 23 days) (Table 1). One participant dropped out after two days of pill consumption, reporting loose stools.

Inclusion criteria consisted of adults capable of understanding study procedures, with no reported illnesses at the time of recruitment, nor use of antibiotics for seven days prior to consent.

All participants completed gastrointestinal questionnaires to determine participant baseline and provide comparison upon study completion. Participants 
Table 1. Participant demographics for probiotic and placebo groups.

\begin{tabular}{cccc}
\hline Gender & Probiotic Group & Placebo Group & Age (years) \\
\hline Male & 11 & 7 & $23.6 \pm 5.3$ \\
Female & 10 & 13 & $22.5 \pm 2.4$ \\
Total & 21 & 20 & $23.0 \pm 3.9$ \\
\hline
\end{tabular}

Participant ages ranged from 19 - 42 years. One participant dropped out after two days of pill consumption.

were provided a booklet containing a copy of signed consent, serving size of typical foods, food diary pages, Bristol stool charts and bowel movement recording forms. Participants were instructed to utilize the serving size and Bristol stool charts to aid in food intake and bowel movement documentation, respectively.

Routine venipuncture procedures were used to collect $15 \mathrm{~mL}$ of a 12-hour fasted blood sample at the beginning and completion of the study. Comprehensive metabolic and lipid panels and C-reactive protein (CRP) were analyzed at Gundersen Health System, La Crosse, WI with a Cobas 6000 (Roche/Hitachi, Indianapolis, IN) automated clinical chemistry and immunoassay system.

Participants collected their first natural bowel movement of the day with a Fisherbrand Commode Specimen Collection System (Thermo Fisher Scientific, Waltham, MA) at the beginning and end of the study. Samples were transported from the participant's home to the Health Science Center at the University of Wisconsin La Crosse campus in supplied bags, processed immediately, and stored at $-80^{\circ} \mathrm{C}$ until DNA extraction or plating was executed.

Participants were instructed to consume the assigned capsule once per day, with or without food. If a dose was missed, participants were instructed to take two capsules the following day. Recurring incidences of missed doses were to be reported to the project leader; none were reported. Participants were instructed to complete a daily food-intake record, which was to include alcohol consumption, throughout the course of the study. The probiotic capsules, provided by Deerland Enzymes Inc., Kennesaw, GA, contained approximately $5 \times 10^{9} \mathrm{CFU} /$ capsule of $B$. subtilis and the placebo capsules contained maltodextrin.

All participants completed the provided gastrointestinal questionnaire to gauge final gastrointestinal symptoms. Participants handed in their completed booklets and were given $\$ 100$ compensation for participation upon completion of the study. Blood was sampled and analyzed as previously described. Fecal samples were collected and analyzed as previously described.

Statistical analysis included the general linear model procedure with within-subjects factor of time (pre- versus post-capsule consumption) and between-subjects factor of capsule type (probiotic versus placebo control group) was conducted with SPSS Version 21.0 (IBM Corp., Armonk, NY). Main effects of time and time by capsule interactions were considered significant at $\mathrm{P}<0.05$.

Fecal plating efforts were divided between the University of Wisconsin-La Crosse and Kennesaw State University. The samples were serially diluted and $10^{-3}, 10^{-5}$, and $10^{-7}$ dilutions were plated. $1 \mathrm{~mL}$ of these two dilutions were 
spread on separate plates to allow growth of B. subtilis, E. coli, L. acidophilus, $B$. longum, and C. albicans.

\section{Results}

Serum fasting glucose was significantly affected by B. subtilis DE111 versus placebo supplementation, with a significant time by capsule interaction $(\alpha \leq 0.05$; $\mathrm{P}$ $=0.012$ ) and a significant decrease in serum glucose in the probiotic group ( $\alpha \leq$ $0.05 ; \mathrm{P}=0.001$ ), but no difference in the placebo group, from pre to post capsule consumption (Figure 1). Triglyceride levels maintained the same within the probiotic group, while the control group displayed a significant increase from pre to post based on a pair T-test ( $\alpha \leq 0.05$; P $\leq 0.042$ ) (Figure 1 ). The cholesterol levels did not change significantly within the standard deviation of the assay for the probiotic group, but showed a significant increase in the control group ( $\alpha$ $\leq 0.05$; $\mathrm{P} \leq 0.025$ ) (Figure 2). There was no significant variation from the normal range of CRP by time or capsule.

While there were no significant differences in gastrointestinal questionnaire answers taken before and after (pre and post) capsule consumption between the

\begin{tabular}{|c|c|c|c|c|c|c|c|c|c|c|}
\hline Group & $\begin{array}{l}\text { BUN Pre } \\
(8-26 \\
m g / d L)\end{array}$ & $\begin{array}{l}\text { BUN Post } \\
(8-26 \\
\mathrm{mg} / \mathrm{dL})\end{array}$ & $\begin{array}{l}\text { Creatinine } \\
\text { Pre }(0.6-1.1 \\
\mathrm{mg} / \mathrm{dL})\end{array}$ & $\begin{array}{l}\text { Creatinine } \\
\text { Post (0.6-1.1 } \\
\mathrm{mg} / \mathrm{dL})\end{array}$ & $\begin{array}{l}\text { Protein } \\
\text { Pre }(6.4 \text { - } \\
8.3 \mathrm{~g} / \mathrm{dL})\end{array}$ & $\begin{array}{l}\text { Protein } \\
\text { Post (6.4 - } \\
8.3 \mathrm{~g} / \mathrm{dL})\end{array}$ & $\begin{array}{l}\text { Albumin } \\
\text { Pre (3.4 - } \\
4.8 \mathrm{~g} / \mathrm{dL})\end{array}$ & $\begin{array}{l}\text { Albumin } \\
\text { Post ( } 3.4- \\
4.8 \mathrm{~g} / \mathrm{dL})\end{array}$ & $\begin{array}{l}++ \text { Glucose } \\
\text { Pre (70 - } 98 \\
\text { mg/dL) }\end{array}$ & $\begin{array}{l}\text { +† Glucose } \\
\text { Post ( } 70-98 \\
\mathrm{mg} / \mathrm{dL}\end{array}$ \\
\hline $\begin{array}{c}\text { DE111 } \\
\text { Probiotic }\end{array}$ & $\begin{array}{c}12.8 \pm \\
0.7\end{array}$ & $13.6 \pm 0.8$ & $0.90 \pm 0.03$ & $0.89 \pm 0.02$ & $\begin{array}{c}7.05 \pm \\
0.06\end{array}$ & $7.11 \pm 0.09$ & $\begin{array}{c}4.59 \pm \\
0.04\end{array}$ & $4.57 \pm 0.06$ & $91.0 \pm 1.0$ & $85.9 \pm 1.4$ \\
\hline $\begin{array}{l}\text { Placebo } \\
\text { Control }\end{array}$ & $\begin{array}{c}12.9 \pm \\
0.8\end{array}$ & $13.1 \pm 1.0$ & $0.80 \pm 0.02$ & $0.80 \pm 0.03$ & $\begin{array}{c}6.78 \pm \\
0.09\end{array}$ & $6.87 \pm 0.11$ & $\begin{array}{c}4.46 \pm \\
0.06\end{array}$ & $4.51 \pm 0.08$ & $86.2 \pm 1.3$ & $85.9 \pm 1.0$ \\
\hline
\end{tabular}
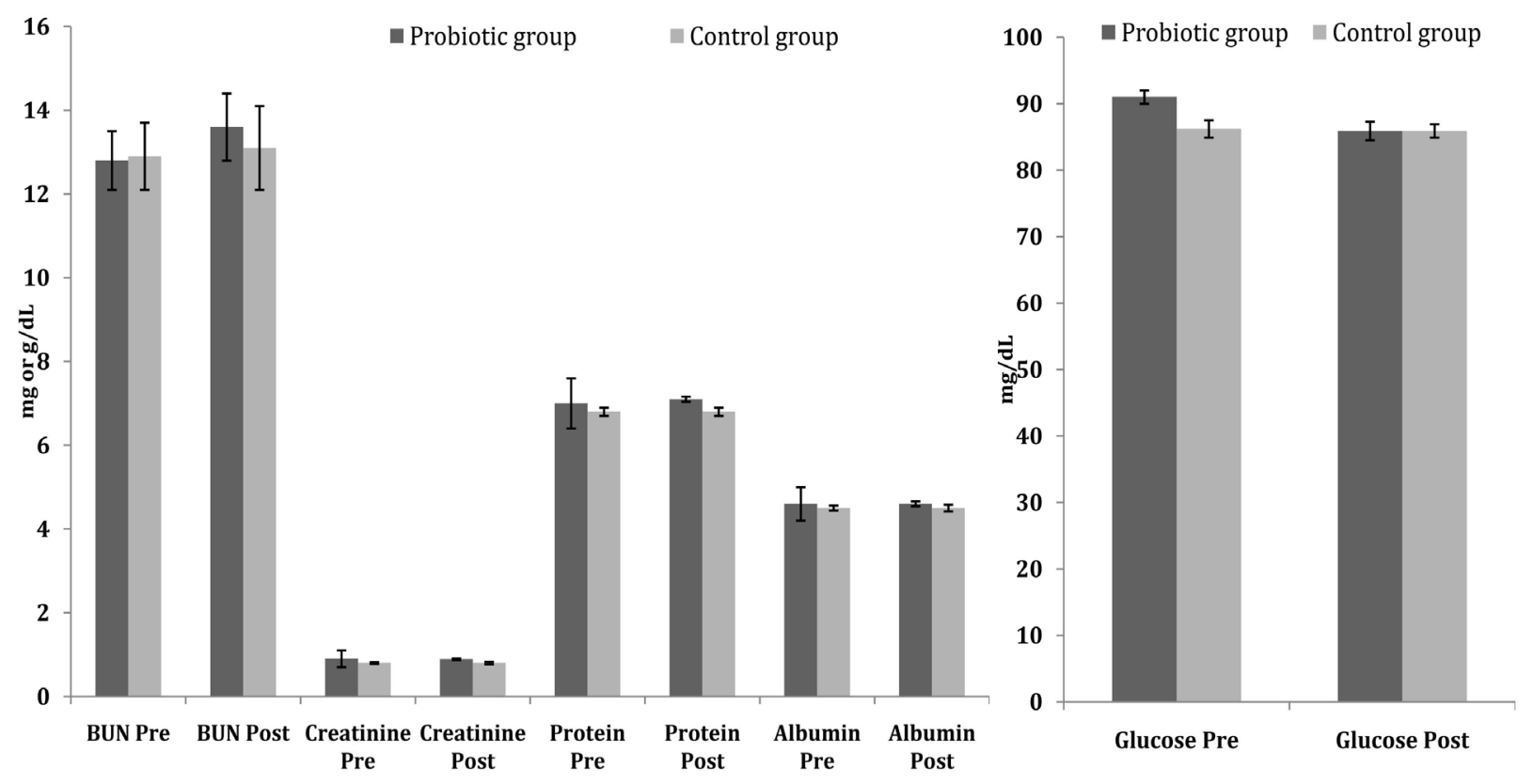

Figure 1. Metabolic parameters pre to post capsule consumption (Y-axis units shown in table). Values are expressed as mean \pm standard error of the mean, $\dagger$ : significant difference with respect to time and $\uparrow \dagger$ : significant difference with respect to time by capsule type. 


\begin{tabular}{|c|c|c|l|l|l|c|c|c|}
\hline Group & $\begin{array}{l}\text { +Bilirubin Pre } \\
(0.1-1.3 \mathrm{mg} / \mathrm{dL})\end{array}$ & $\begin{array}{l}\text { +Bilirubin Post } \\
(0.1-1.3 \mathrm{mg} / \mathrm{dL})\end{array}$ & $\begin{array}{l}\text { ALKP Pre } \\
(\mathrm{IU} / \mathrm{L})\end{array}$ & $\begin{array}{l}\text { ALKP Post } \\
(\mathrm{IU} / \mathrm{L})\end{array}$ & $\begin{array}{l}\text { AST Pre } \\
(0-36 \mathrm{IU} / \mathrm{L})\end{array}$ & $\begin{array}{l}\text { AST Post } \\
(0-36 \mathrm{IU} / \mathrm{L})\end{array}$ & $\begin{array}{l}\text { ALT Pre } \\
(0-40 \mathrm{IU} / \mathrm{L})\end{array}$ & $\begin{array}{l}\text { ALT Post } \\
(0-40 \mathrm{IU} / \mathrm{L})\end{array}$ \\
\hline $\begin{array}{c}\text { DE } 111 \\
\text { Probiotic }\end{array}$ & $0.83 \pm 0.09$ & $0.68 \pm 0.08$ & $65.1 \pm 4.7$ & $62.7 \pm 4.3$ & $19.5 \pm 1.4$ & $18.3 \pm 0.8$ & $16.3 \pm 0.8$ & $14.8 \pm 1.0$ \\
\hline $\begin{array}{c}\text { Placebo } \\
\text { Control }\end{array}$ & $0.51 \pm 0.07$ & $0.45 \pm 0.04$ & $63.8 \pm 2.9$ & $62.9 \pm 3.1$ & $21.6 \pm 1.4$ & $23.2 \pm 2.9$ & $15.6 \pm 1.3$ & $18.9 \pm 3.5$ \\
\hline
\end{tabular}
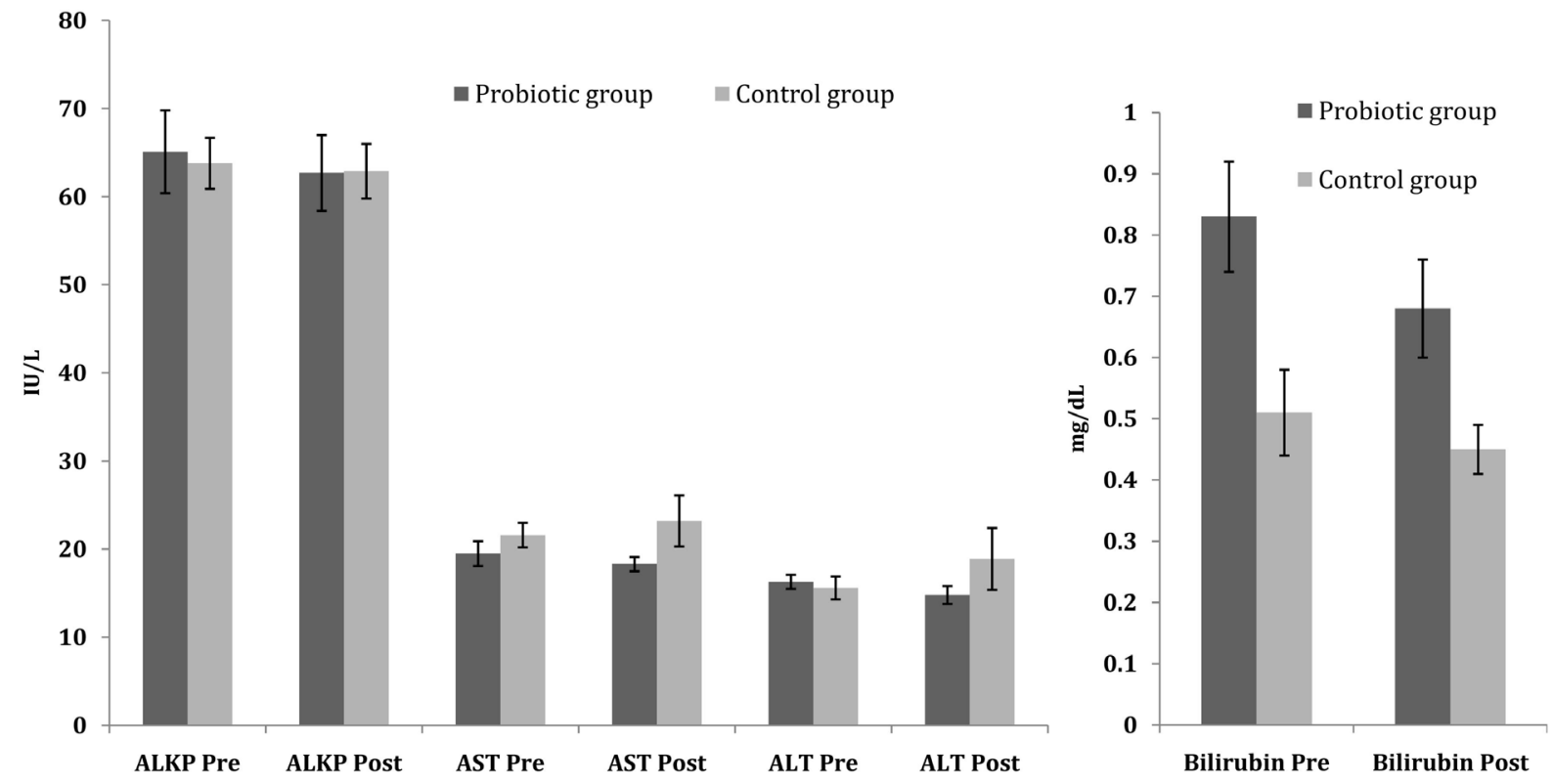

Figure 2. Liver and lipid parameters pre to post capsule consumption. Values are expressed as mean \pm standard error of the mean, $\dagger$ : significant difference with respect to time and $\dagger \dagger$ : significant difference with respect to time by capsule type.

probiotic and placebo groups, there were some notable variations between the two groups. Throughout the course of capsule consumption, the probiotic group reported a slight decrease in bothersome nausea and rumbling while the placebo group reported a slight increase in symptoms in these questions.

The placebo group had a significant increase in average bowel movements per day when compared to the probiotic group over the course of capsule consumption ( $\alpha \leq 0.05 ; \mathrm{P}=0.015)$, but did not demonstrate a significant change in the type. Both groups reported feelings of incomplete bowel movements less often in the questionnaire taken before capsule consumption compared to in the same questionnaire taken after capsule consumption.

PCR assays yielded minimal results for the presence of B. subtilis, with only four participants' fecal samples positive for $B$. subtilis, all were post-consumption samples within the probiotic group. There was no significant difference between the probiotic and placebo groups pre- to post-capsule consumption. However, there was an upward trend of starting quantity in the probiotic group compared to the placebo group (Figure 3).

There was a significant difference present for $B$. subtilis with respect to time within the probiotic group ( $\alpha \leq 0.05 ; \mathrm{P}=0.0053$ ) and a significant difference between participants factor of capsule type (Probiotic versus placebo control 


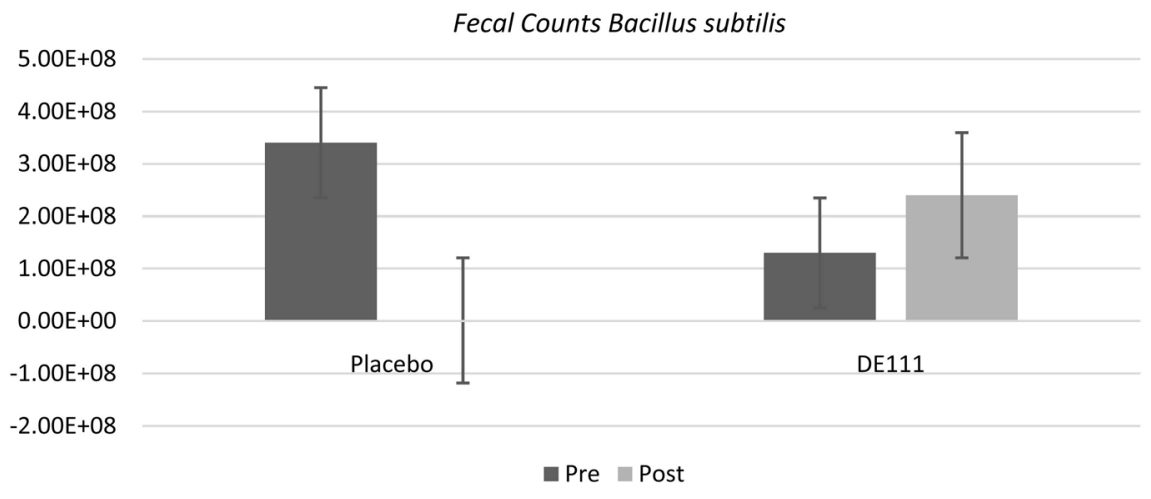

(a)

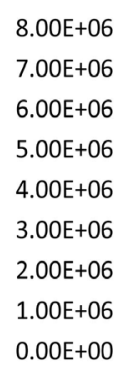

Fecal Counts Escherichia coli

$8.00 E+06$
$7.00 E+06$
$6.00 E+06$
$5.00 E+06$
$4.00 E+06$
$3.00 E+06$
$2.00 E+06$
$1.00 E+06$
$0.00 E+00$

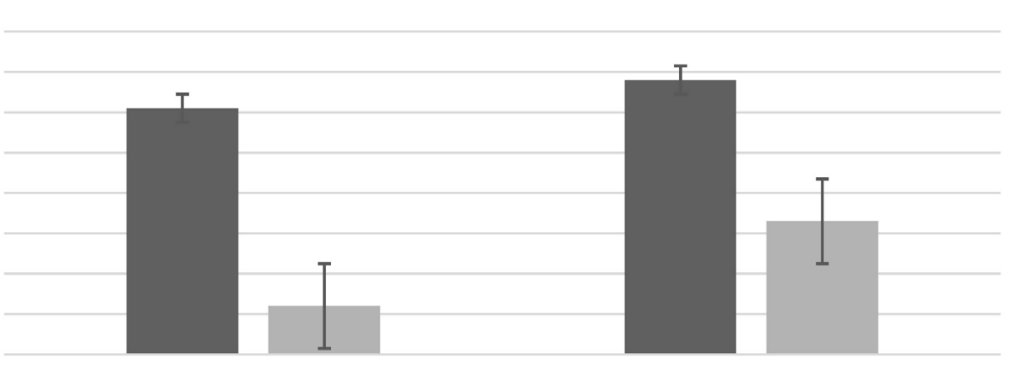

Placebo

DE111

- Pre $\square$ Post

(b)

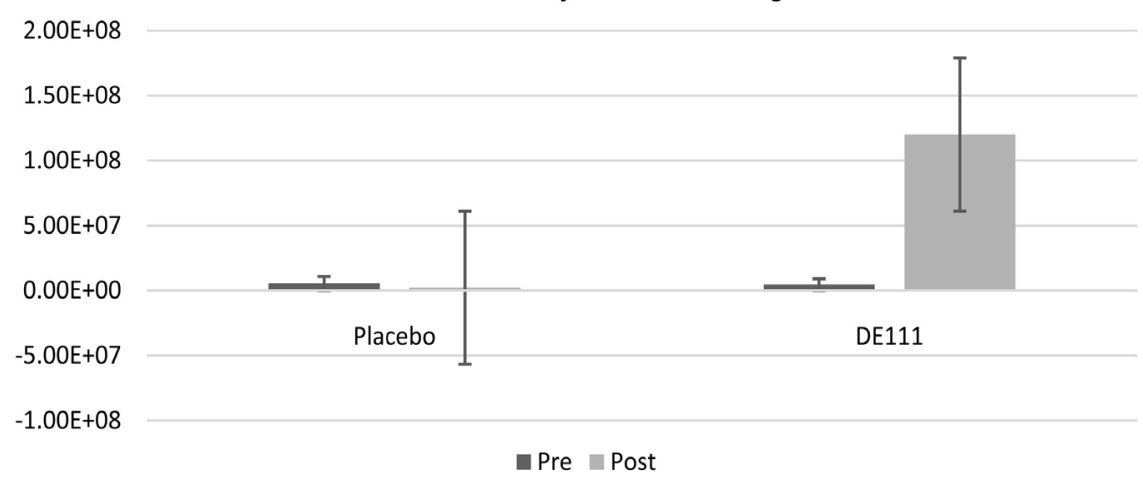

(c)

Figure 3. Fecal plate counts (CFU) pre and post placebo or B. subtilis (DE111) consumption.

group) ( $\alpha \leq 0.05 ; \mathrm{P}=0.049$ ). Participants who were administered the placebo demonstrated a decrease in intestinal levels of the probiotic Bifidobacterium, while those who were administered the probiotic experienced a significant increase with respect to time within the probiotic group $(\alpha \leq 0.10 ; \mathrm{P}=0.10)$ and a significant difference with capsule type (Probiotic versus placebo group) ( $\alpha \leq$ $0.10 ; \mathrm{P}=0.08$ ). Subjects did not demonstrate a significant difference in levels of E. coli in either the placebo or probiotic group (Figure 3). No noticeable differences were observed for either Lactobacillus or yeast. 


\section{Discussion}

The study population was predominantly a sample of college students, who were willing to provide stool and blood samples, fill out detailed diet and stool records, and complete the GI questionnaire before and after (pre and post) capsule consumption for a $\$ 100$ honorarium. College student dietary habits are notoriously irregular, but can be especially so near the end of an academic unit (quarter or semester), when schedules and stress levels change due to final exams. During the time of final exams and before the final sample collections, there was an increase in consumption of alcohol, candy, and fatty foods.

The blood parameters examined were expected to remain the same throughout the study. The only exceptions to this hypothesis were serum glucose and triglycerides. One possibility for the changes observed in serum glucose levels could be from 1-Deoxynojirimycin (DNJ). DNJ is a compound isolated from $B$. subtilis that, when fed to bovine calves, improved diabetic conditions by improving insulin sensitivity [12]. In addition, freeze-dried cultures of L. acidophilus, B. lactic, and L. rhamnosus were administered, by gavage twice daily for three days, to male Wistar rats. The delivered probiotics led to reduced blood glucose levels by up to two-fold in rats with elevated glucose levels.

There was a significant increase in the average number of bowel movements per day within the control group. In addition, no significant difference in either group for bowel movement type was seen. The use of probiotics may alleviate symptoms associated with antibiotic-associated diarrhea, traveler's diarrhea, and symptoms associated with irritable bowel syndrome [13] [14] [15] [16]. Bowel movement types can be associated with ease of excretion, in addition to efficient elimination of waste material. There was a small, but not significant difference in bowel movement type between the probiotic, averaging a softer, smoother type 4 , and control group, averaging a slightly harder, lumpier type 3 , throughout the course of the study.

Daily ingestion of one capsule containing approximately $5 \times 10^{9}$ colony forming units (CFU)/capsule of B. subtilis was well tolerated in healthy young adults consuming their usual and variable diets, as reflected by blood levels of important biomarkers. Markers of systemic acceptance, such as CRP and liver enzymes, remained within acceptable ranges and gastrointestinal symptoms and bowel habits, if anything, improved with probiotic capsule consumption. Though this study did not support a beneficial effect of this probiotic on lipid profile in this healthy largely normolipidemic population, there could still be beneficial effects, as demonstrated in some studies, in a hyperlipidemic population. LDL increased in both groups, which may have been a reflection of poor eating habits nearing the end of the semester, but increased less in the probiotic group. Triglycerides levels were maintained in the probiotic group, but increased significantly in the control group. Finally, consumption of B. subtilis in the manner described herein, may improve glucose tolerance, corroborating the findings of non-human animal in vivo and in vitro studies by [6] and [12], respectively. This 
probiotic is a safe, efficacious dietary supplement for immunity, digestive health, and as a competitive exclusion agent. Daily consumption of the B. subtilis probiotic supplement resulted in a significant effect on gut microflora measured prior to and after capsule consumption in regards to B. subtilis and Bifidobacterium.

\section{Conflicts of Interest}

The author declares no conflicts of interest regarding the publication of this paper.

\section{References}

[1] Bengmark, S. (1998) Ecological Control of the Gastrointestinal Tract. The Role of Probiotic Flora. Gut, 42, 2. https://doi.org/10.1136/gut.42.1.2

[2] Neish, A.S. (2009) Microbes in Gastrointestinal Health and Disease. Gastroenterology, 136, 65-80. https://doi.org/10.1053/j.gastro.2008.10.080

[3] Rolfe, R.D. (2000) The Role of Probiotic Cultures in the Control of Gastrointestinal Health. Journal of Nutrition, 130, 396S-402S. https://doi.org/10.1093/jn/130.2.396S

[4] Geier, M., Butler, R. and Howarth, G. (2007) Inflammatory Bowel Disease: Current Insights into Pathogenesis and New Therapeutic Options; Probiotics, Prebiotics and Synbiotics. International Journal of Food Microbiology, 115, 1-11. https://doi.org/10.1016/j.ijfoodmicro.2006.10.006

[5] Rauch, M. and Lynch, S. (2012) The Potential for Probiotic Manipulation of the Gastrointestinal Microbiome. Current Opinions in Biotechnology, 23, 192-201. https://doi.org/10.1016/j.copbio.2011.11.004

[6] Al-Salami, H., Butt, G., Fawcett, J.P., Tucker, I.G., Golocorbin-Kon, S. and Mikov, M. (2008) Probiotic Treatment Reduces Blood Glucose Levels and Increases Systemic Absorption of Gliclazide in Diabetic Rats. European Journal of Drug Metabolism and Pharmacokinetics, 33, 101-106. https://doi.org/10.1007/BF03191026

[7] Srinivasan, K. and Elna, M.B. (2019) Insights into the Role of Bacteria in Vitamin A Biosynthesis: Future Research Opportunities. Critical Reviews in Food Science and Nutrition. https://doi.org/10.1080/10408398.2018.1546670

[8] Goldin, B.R. and Gorbach, S.L. (2008) Clinical Indications for Probiotics: An Overview. Clinical Infectious Disease, 46, S96-S100. https://doi.org/10.1086/523333

[9] Ranadheera, R.D.C.S., Baines, S.K. and Adams, M.C. (2010) Importance of Food in Probiotic Efficacy. Food Research International, 43, 1-7. https://doi.org/10.1016/j.foodres.2009.09.009

[10] Casula, G. and Cutting, S.M. (2002) Bacillus Probiotics: Spore Germination in the Gastrointestinal Tract. Applied and Environmental Microbiology, 68, 2344-2352. https://doi.org/10.1128/AEM.68.5.2344-2352.2002

[11] Rauch, M. and Lynch, S.V. (2012) The Potential for Probiotic Manipulation of the Gastrointestinal Microbiome. Current Opinions in Biotechnology, 23, 192-201. https://doi.org/10.1016/j.copbio.2011.11.004

[12] Lee, S.M. (2013) 1-Deoxynojirimycin Isolated from a Bacillus subtilis Stimulates Adiponectin and GLUT4 Expressions in 3T3-L1 Adipocytes. Journal of Microbiology and Biotechnology, 23, 637-643. https://doi.org/10.4014/jmb.1209.09043

[13] Hong, H.A., Duc, L.H. and Cutting, S.M. (2005) The Use of Bacterial Spore Formers as Probiotics: Table 1. FEMS Microbiology Reviews, 29, 813-835. 
https://doi.org/10.1016/j.femsre.2004.12.001

[14] Jain, D. and Chaudhary, H. (2014) Clinical Significance of Probiotics in Human. International Journal of Nutrition, Pharmacology, Neurological Diseases, 4, 11-22. https://doi.org/10.4103/2231-0738.124610

[15] Saarela, M., Mogensen, G., Fondén, R., Mättö, J. and Mattila-Sandholm, T. (2000) Probiotic Bacteria: Safety, Functional and Technological Properties. Journal of Biotechnology, 84, 197-215. https://doi.org/10.1016/S0168-1656(00)00375-8

[16] Schrezenmeir, J. and de Vrese, M. (2001) Probiotics, Prebiotics, and Synbiotics-Approaching a Definition. American Journal of Clinical Nutrition, 73, 361s-364s. https://doi.org/10.1093/ajcn/73.2.361s 